\title{
Structural evolution of plasma sprayed amorphous Li4Ti5012 electrode and ceramic/polymer composite electrolyte during electrochemical cycle of quasi-solid-state lithium battery
}

\section{Xi Wu}

Guangxi University of Science and Technology https://orcid.org/0000-0002-3982-1098

\section{Xinghua Liang}

Guangxi University of Science and Technology

XiaoFeng Zhang ( $\sim$ zxf200808@126.com)

Guangdong Academy of Science https://orcid.org/0000-0002-7321-9631

\section{Lingxiao Lan}

Guangxi University of Science and Technology

\section{Suo Li}

Guangxi University of Science and Technology

\section{Qixin Gai}

Guangxi University of Science and Technology

\section{Research Article}

Keywords: Plasma spraying, Li4Ti5012 electrode, Ceramic/polymer composite electrolyte, Electrochemical cycle, Quasi-solid-state lithium battery

Posted Date: September 28th, 2020

DOI: https://doi.org/10.21203/rs.3.rs-82747/v1

License: (c) (i) This work is licensed under a Creative Commons Attribution 4.0 International License. Read Full License

Version of Record: A version of this preprint was published at Journal of Advanced Ceramics on February 6th, 2021. See the published version at https://doi.org/10.1007/s40145-020-0447-9. 


\section{Abstract}

Solid-state batteries are one of the effective way to solve the safety of traditional power and energy storage batteries with flammable liquid electrolyte. This time, a quasi-solid-state lithium battery is assembled by plasma sprayed amorphous Li 4 Ti 5012 (LTO) electrode and ceramic/polymer composite electrolyte with a little liquid electrolyte $(10 \mu \mathrm{l} / \mathrm{cm} 2)$ to provide the outstanding electrochemical stability and better than normal interface contact. SEM, STEM, TEM and EDS were used to analyze the structure evolution and performance of plasma sprayed amorphous LTO electrode and ceramic/polymer composite electrolyte before and after electrochemical experiments. By comparing the electrochemical performance of the amorphous LTO electrode and the traditional LTO electrode, the electrochemical behavior of different electrodes is studied. The results show that plasma spraying can prepare an amorphous Li 4 Ti 5012 electrode coating of about $8 \mu \mathrm{m}$. After 200 electrochemical cycles, the structure of the electrode evolved, and the inside of the electrode fractured and cracks expanded, because of recrystallization at the interface between the rich fluorine compounds and the amorphous LTO electrode. Similarly, the ceramic/polymer composite electrolyte has undergone structural evolution after 200 cycles test. The electrochemical cycle results show that the cycle stability, capacity retention rate, coulomb efficiency, and internal impedance of amorphous LTO electrodes are better than traditional LTO electrode. This innovative and facile quasi-solid-state strategy is aimed to promote the intrinsic safety and stability of working lithium battery, shedding light on the development of next-generation high-performance solidstate lithium batteries.

\section{Full Text}

This preprint is available for download as a PDF.

\section{Figures}

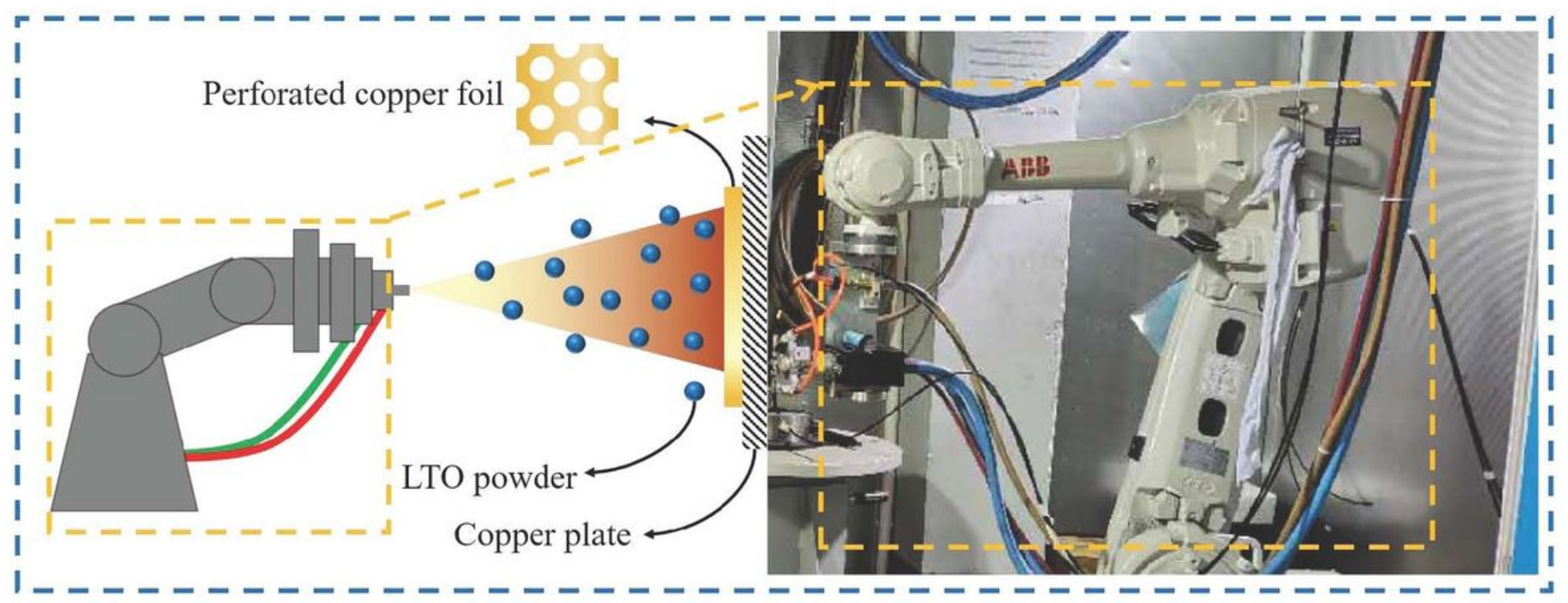


Figure 1

Schematic image of preparing LTO electrode by plasma spraying.

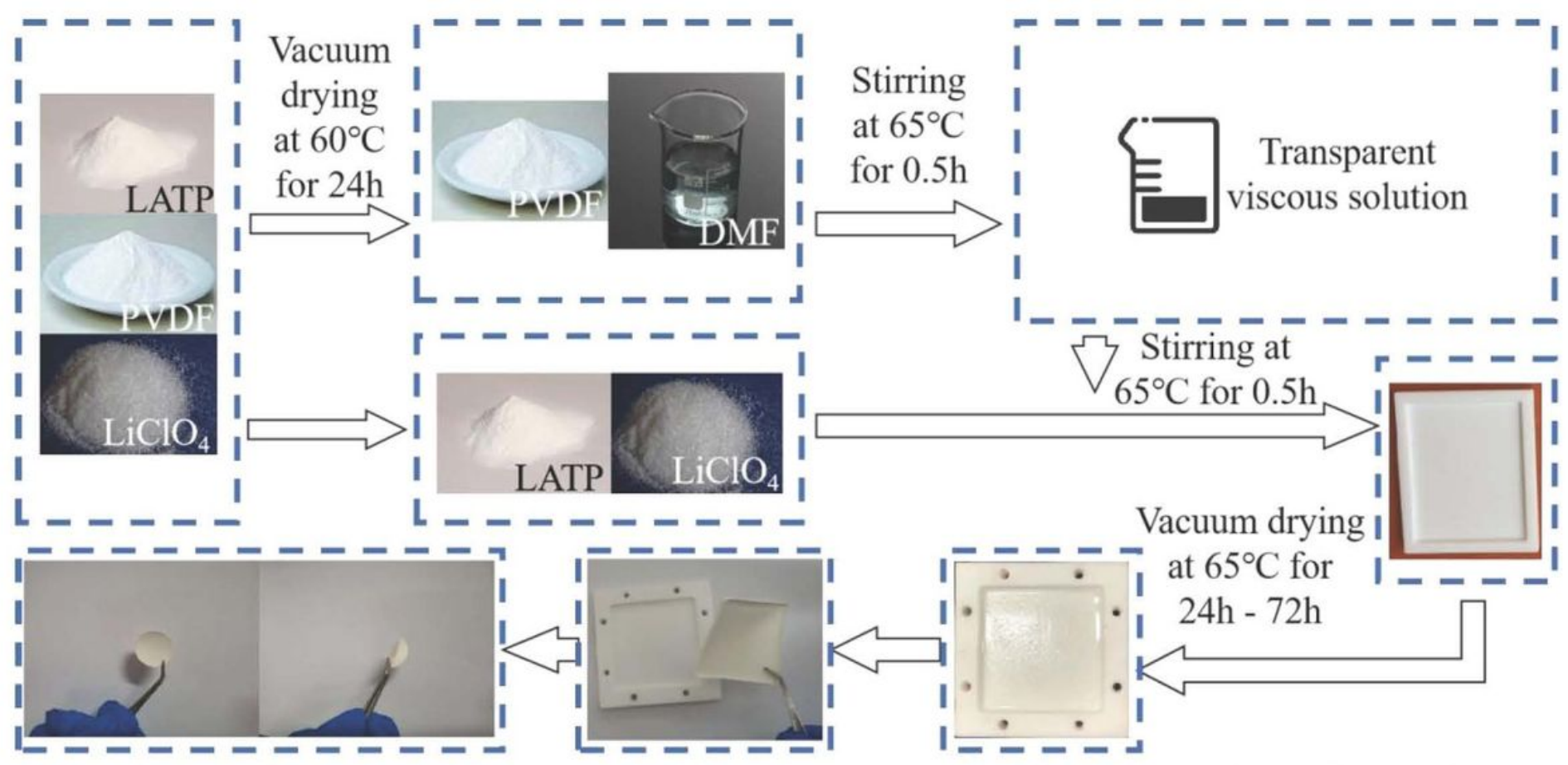

Figure 2

Illustration of the preparation process of flexible electrolyte film with ceramic/polymer composite.

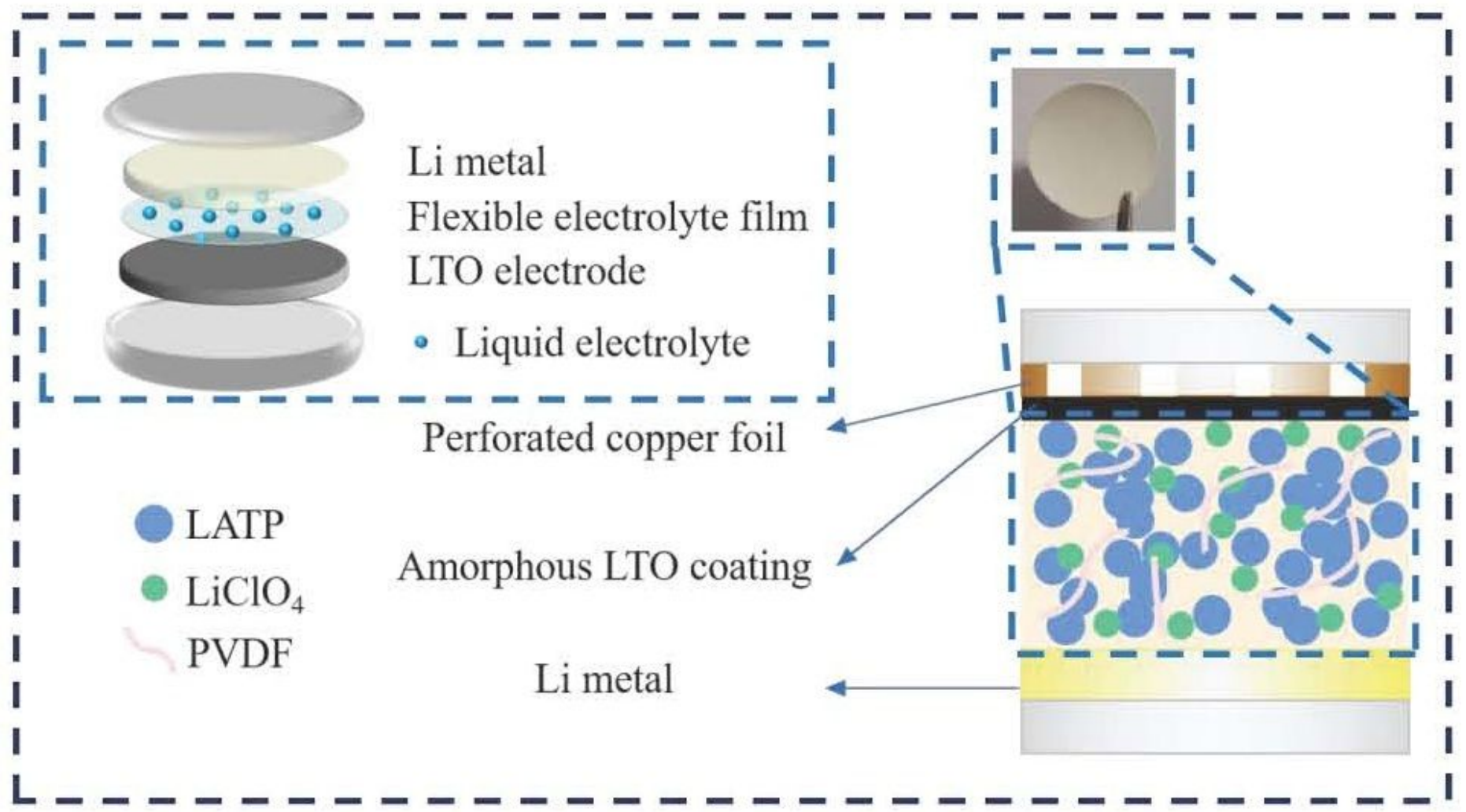


Figure 3

Schematic image of LTO|ceramic/polymer composite electrolyte|Li quasi-solid battery assembly.
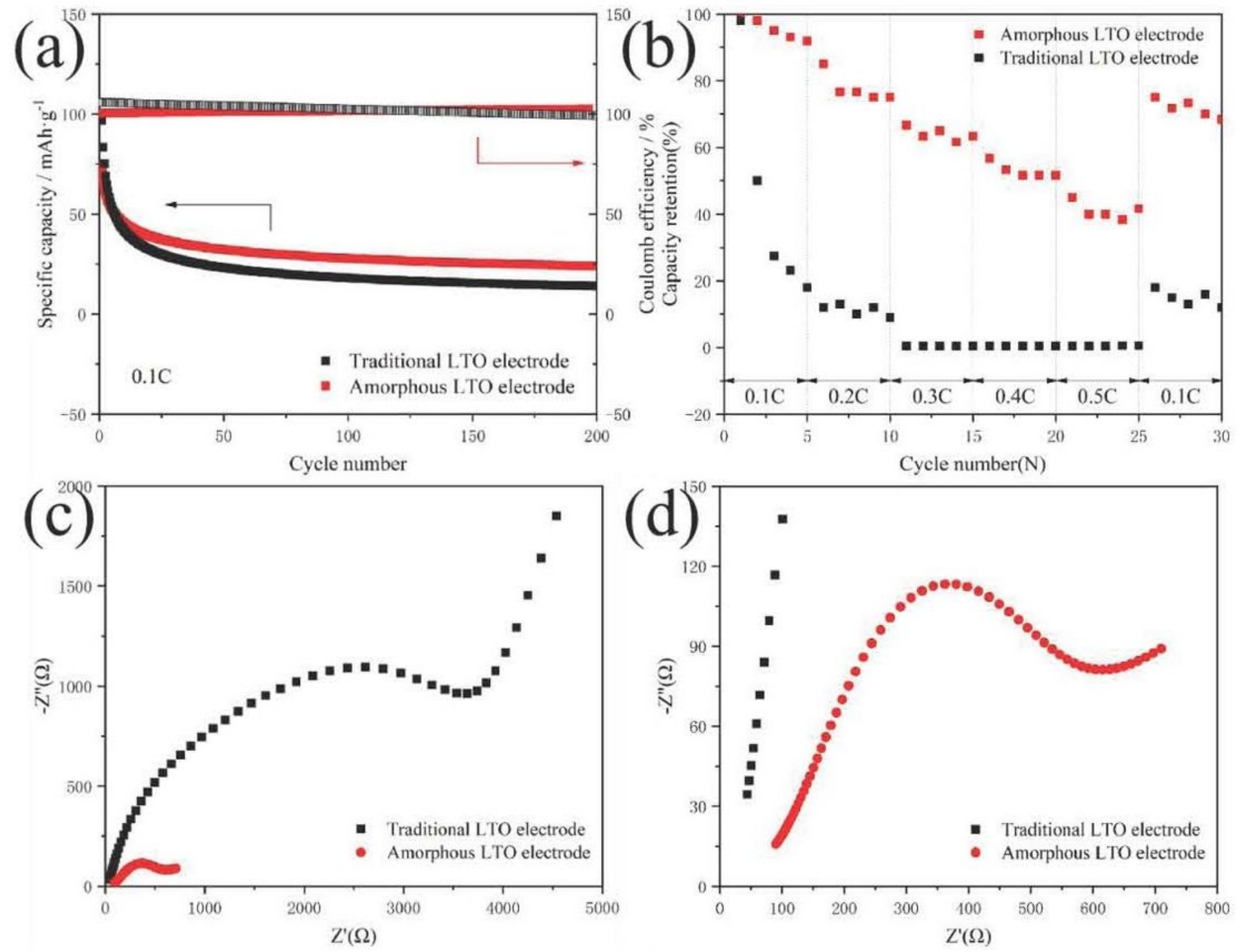

\section{Figure 4}

Comparison of electrochemical performance between amorphous and traditional LTO electrodes, (a)discharge performance and coulomb efficiency under 200 cycles test, (b)capacity retention, (c)EIS, (d)partial enlarged view of EIS. 

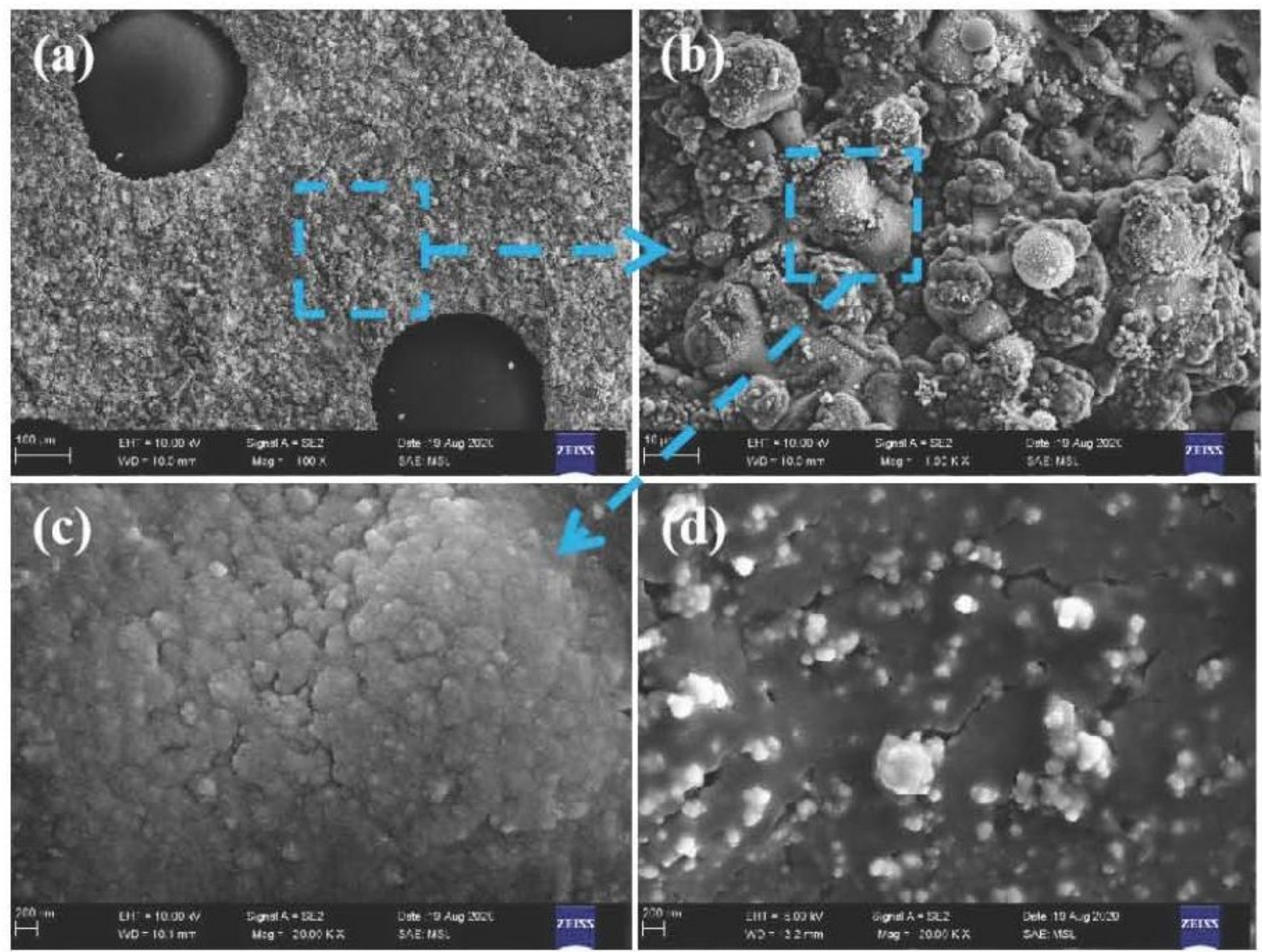

\section{Figure 5}

SEM images of amorphous LTO electrode surface, (a) original spray state image, (b) magnified image of figure $a,(c)$ partial magnified image of figure b, (d) surface structure image after 200 cycles test. 

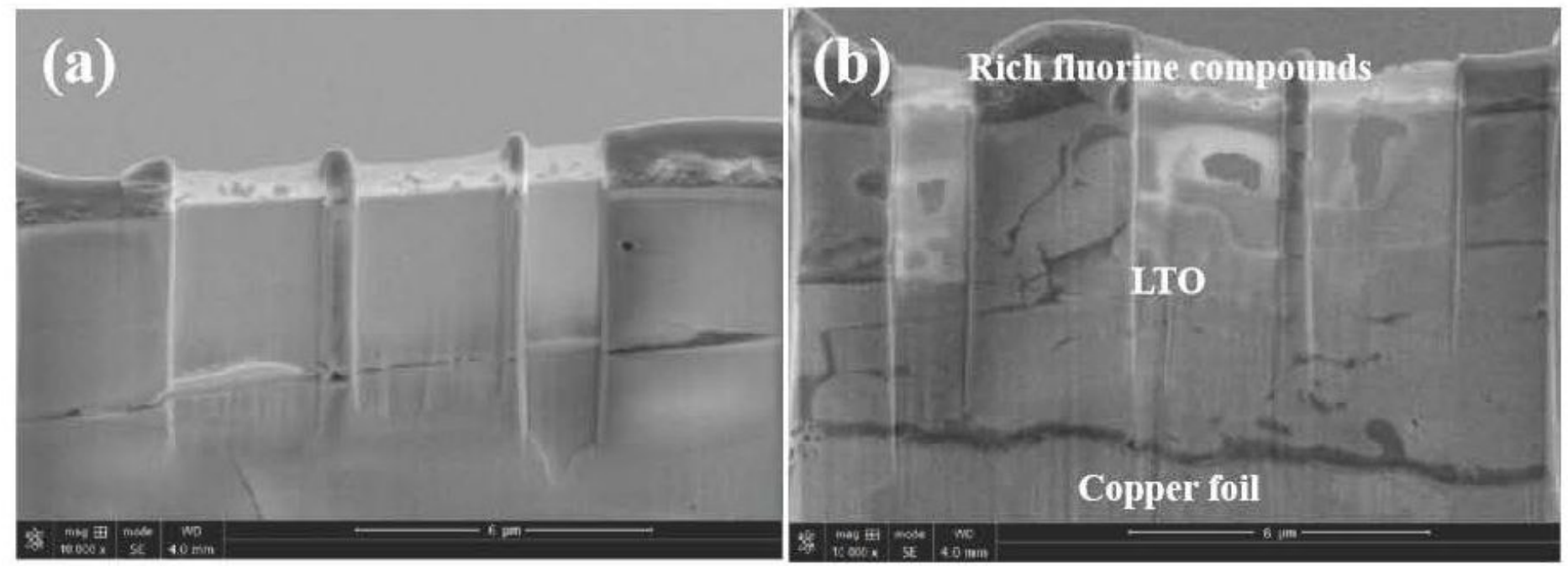

Figure 6

FIB-SEM of amorphous LTO electrode before (a) and after (b) 200 cycles test. 


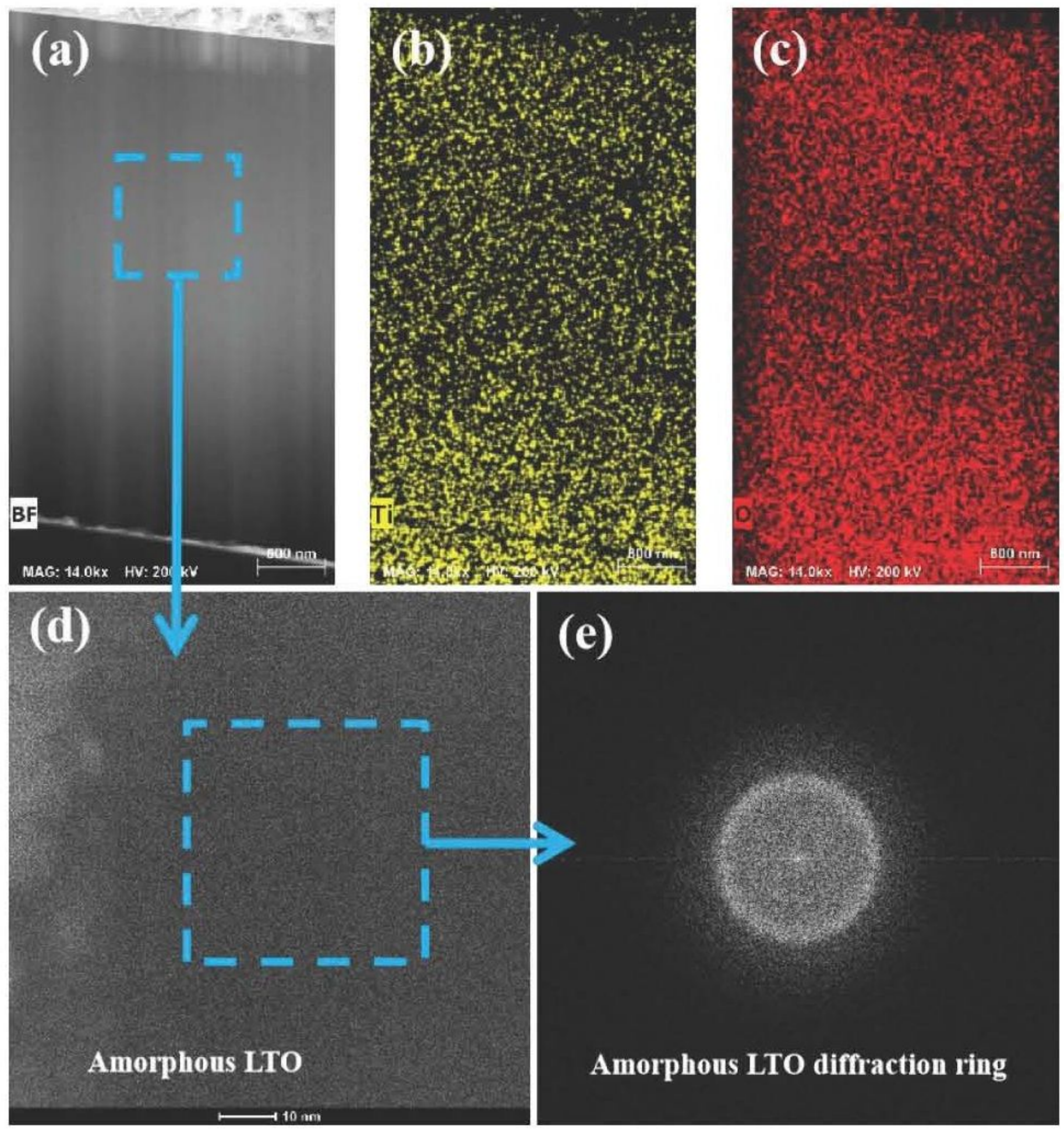

\section{Figure 7}

The cross-section (a) and corresponding elemental mappings (b-c) of the original amorphous LTO electrode, the TEM image of the corresponding marked area (d) and the amorphous diffraction ring (e). 


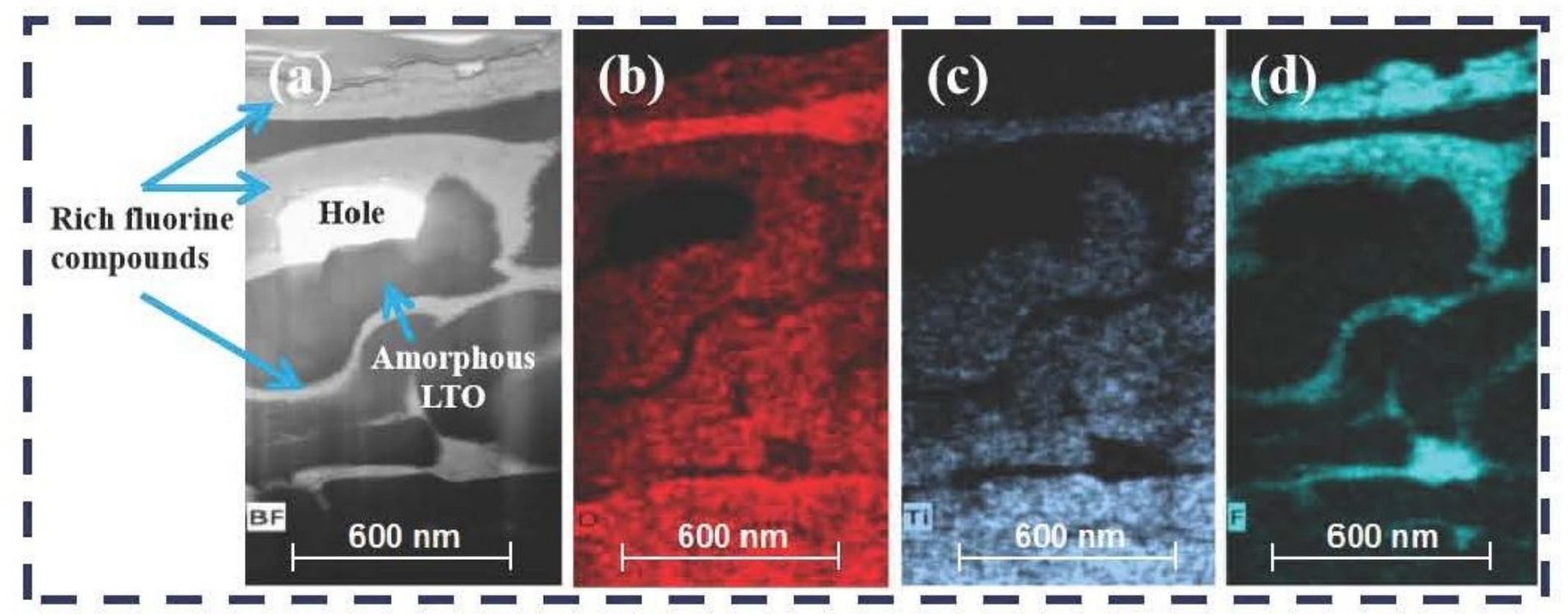

\section{Figure 8}

Cross-sectional view of amorphous LTO electrode after 200 cycles test and corresponding elemental mappings, (a) cross-section, (b) 0 elemental mapping, (c) Ti elemental mapping, (d) F elemental mapping.
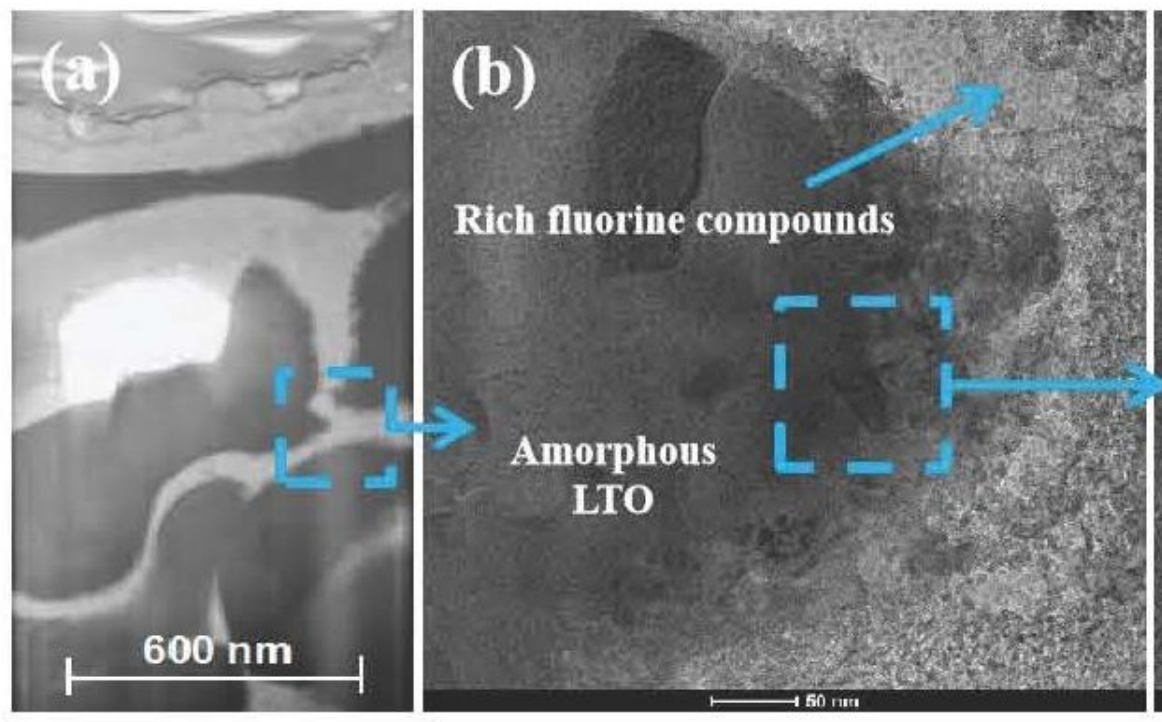

(c) Recrystalline LTO
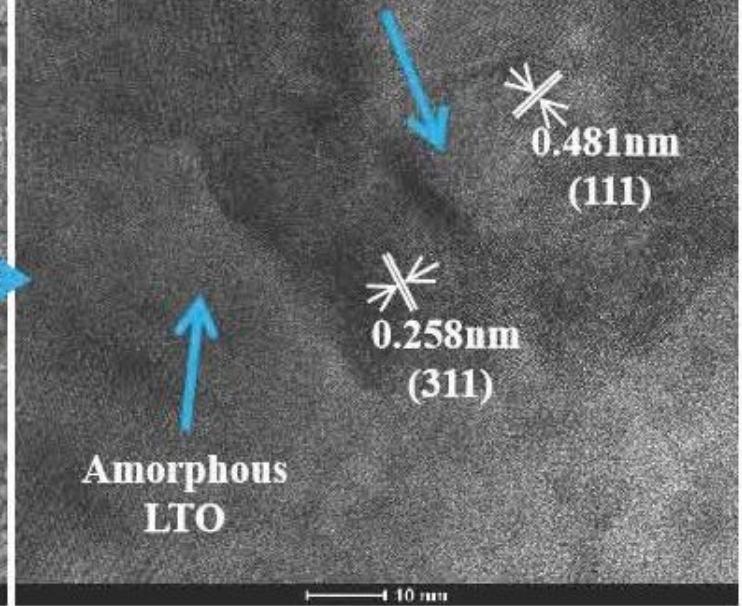

\section{Figure 9}

Cross section (a), internal state (b) and phase analysis (c) of amorphous LTO electrode coating through TEM after 200 cycles test. 


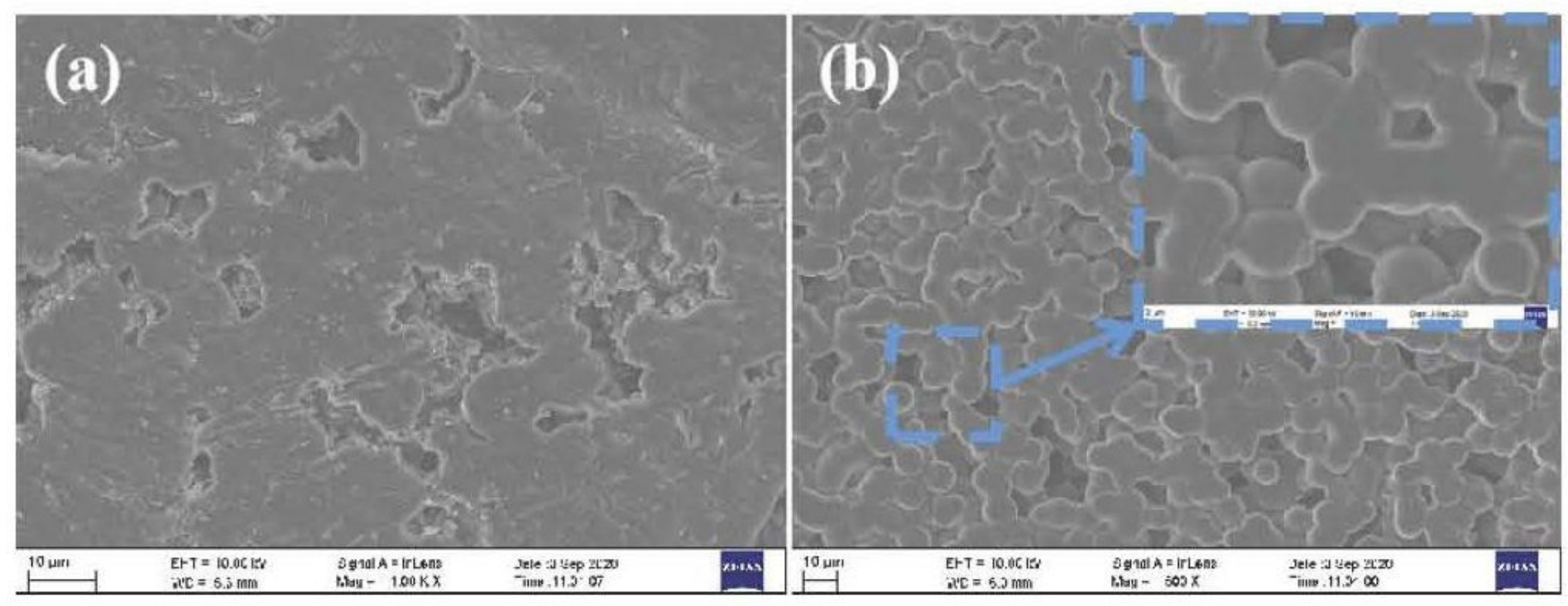

Figure 10

SEM images of the structural evolution of ceramic/polymer composite electrolyte before (a) and after (b) 200 cycles test. 